\title{
Direct cAMP Signaling through G-Protein-Coupled Receptors Mediates Growth Cone Attraction Induced by Pituitary Adenylate Cyclase-Activating Polypeptide
}

\author{
Carmine Guirland, ${ }^{\star}$ Kenneth B. Buck, ${ }^{\star}$ Jean A. Gibney, Emanuel DiCicco-Bloom, and James Q. Zheng \\ Department of Neuroscience and Cell Biology, University of Medicine and Dentistry of New Jersey-Robert Wood Johnson Medical School, Piscataway, New \\ Jersey 08852
}

Developing axons are guided to their appropriate targets by environmental cues through the activation of specific receptors and intracellular signaling pathways. Here we report that gradients of pituitary adenylate cyclase-activating polypeptide (PACAP), a neuropeptide widely expressed in the developing nervous system, induce marked attraction of Xenopus growth cones in vitro. PACAP exerted its chemoattractive effects through PAC1, a PACAP-selective G-protein-coupled receptor (GPRC) expressed at the growth cone. Furthermore, the attraction depended on localized cAMP signaling because it was completely blocked either by global elevation of intracellular cAMP levels using forskolin or by inhibition of protein kinase A using specific inhibitors. Moreover, local direct elevation of intracellular cAMP by focal photolysis of caged cAMP compounds was sufficient to induce growth cone attraction. On the other hand, blockade of $\mathrm{Ca}^{2+}$, phospholipase $\mathrm{C}$, or phosphatidyl inositol-3 kinase signaling pathways did not affect PACAP-induced growth cone attraction. Finally, PACAP-induced attraction also involved the Rho family of small GTPases and required local protein synthesis. Taken together, our results establish cAMP signaling as an independent pathway capable of mediating growth cone attraction induced by a physiologically relevant peptide acting through GPCRs. Such a direct cAMP pathway could potentially operate in other guidance systems for the accurate wiring of the nervous system.

Key words: growth cone turning; axon guidance; intracellular signaling; second messengers; $\mathrm{PAC} 1 ; \mathrm{Ca}^{2+}$

\section{Introduction}

During navigation toward target cells, the growth cone senses spatially and temporally distributed cues and subsequently steers the axon in the appropriate direction (Tessier-Lavigne and Goodman, 1996). Although the cellular mechanisms underlying directional sensing and steering of the growth cone remain to be elucidated, extracellular cues likely activate growth cone surface receptors in an asymmetric manner to elicit localized intracellular signaling events, which ultimately control cytoskeletal activities to steer the growth cone. Previous studies have established that localized $\mathrm{Ca}^{2+}$ signaling mediates growth cone turning induced by a number of extracellular cues (Zheng et al., 1994b; Ming et al., 1997b; Song et al., 1997; Kuhn et al., 1998; Hong et al., 2000; Gomez et al., 2001). We have further demonstrated that local $\mathrm{Ca}^{2+}$ signals are sufficient to instruct growth cone turning, and the global level of intracellular $\mathrm{Ca}^{2+}$ at the growth cone can modulate the turning behavior (Zheng, 2000). cAMP, on the other hand, has been shown to modulate $\mathrm{Ca}^{2+}$-dependent growth cone turning responses: global increases or decreases in cAMP result in switching of turning responses from repulsion to attraction or vice versa (for review, see Song and Poo, 1999). However, it is not clear whether local cAMP signals are necessary

Received 0ct. 30, 2002; revised Dec. 18, 2002; accepted Dec. 27, 2002

This work was supported by grants from the National Institutes of Health and the National Foundation of Science.

${ }^{*}$ C.G. and K.B.B. contributed equally to this project.

Correspondence should be addressed to Dr. James Zheng, Department of Neuroscience and Cell Biology, University of Medicine and Dentistry of New Jersey-Robert Wood Johnson Medical School, 675 Hoes Lane, Piscataway, NJ 08854.E-mail: james.zheng@umdnj.edu.

Copyright $\odot 2003$ Society for Neuroscience $\quad 0270-6474 / 03 / 232274-10 \$ 15.00 / 0$ and sufficient to directly mediate growth cone turning induced by guidance cues. Early investigations using extracellular gradients of membrane-permeant cAMP analogs suggested that the cAMP pathway could influence the direction of growth cone extension (Gundersen and Barrett, 1980; Lohof et al., 1992). However, because $\mathrm{Ca}^{2+}$ - and cAMP-signaling pathways interact (Eliot et al., 1993; Cooper et al., 1995; Wayman et al., 1995; Mons et al., 1998; Haug et al., 1999; Gorbunova and Spitzer, 2002), gradients of cAMP analogs could potentially activate $\mathrm{Ca}^{2+}$ or other signaling pathways to elicit growth cone attraction. Conclusive and direct evidence for local cAMP signals to directly mediate growth cone turning remain to be demonstrated.

In many cell types, cAMP production often results from activation of adenylate cyclase by the $\mathrm{G} \alpha$ s subunit of heterotrimeric G-proteins. The neuropeptide pituitary adenylate cyclaseactivating polypeptide (PACAP) stimulates the production of cAMP by binding to three heptahelical G-protein-coupled receptor (GPCR) family members, including PAC1, VPAC1, and VPAC2 (Harmar and Lutz, 1994; Vaudry et al., 2000). PACAP, a member of the vasoactive intestinal polypeptide (VIP)-glucagon-secretin superfamily (Arimura, 1992; Sherwood et al., 2000), and its receptors are conserved across species (Miyata et al., 1989; Chartrel et al., 1991) and expressed in the nervous, digestive, and reproductive systems. PACAP ligand-receptor interactions can lead to various biological functions mediated by several signaling pathways (Vaudry et al., 2000; Waschek, 2002). In the nervous system, PACAP and its receptors exert profound influences on neurotransmission, neuromodulation, neurogenesis, and neurite outgrowth (for review, see Waschek, 2002). Be- 
cause PACAP activation of its receptors stimulates the production of cAMP and enhances neurite outgrowth, we hypothesized that localized GPCR activation by extracellular PACAP gradients could induce growth cone turning responses. We now report that extracellular PACAP gradients effectively attract Xenopus growth cones by activating PAC1 GPCRs present at the growth cone. Significantly, PACAP-induced growth cone attraction is directly mediated by localized cAMP signaling; neither the $\mathrm{Ca}^{2+}$, phospholipase C (PLC), nor phosphatidyl inositol (PI)-3 kinase signaling pathway is involved in PACAP-induced attraction. It is conceivable that the CAMP pathway, independent of $\mathrm{Ca}^{2+}$ signaling, may mediate the actions of other guidance cues, especially those involving GPCRs.

\section{Materials and Methods}

Cell culture. Dissociated cells from the neural tube tissue of 1-d-old Xenopus embryos (Spitzer and Lamborghini, 1976) were plated on glass coverslips precoated with poly-D-lysine and laminin (Zhang and Mason, 1998). Briefly, rectangular coverslips (No. $1,40 \times 22 \mathrm{~mm}^{2}$; VWR Scientific) were incubated with poly-D-lysine $(0.5 \mathrm{mg} / \mathrm{ml}$; Specialty Media, Freehold, NJ) for $1 \mathrm{hr}$ at room temperature, rinsed three times with $\mathrm{H}_{2} \mathrm{O}$, and allowed to dry completely. The coverslips were then incubated with laminin $\left(20 \mu \mathrm{g} / \mathrm{ml}\right.$; Sigma, St. Louis, MO) for $1 \mathrm{hr}$ at $37^{\circ} \mathrm{C}$, rinsed with $\mathrm{Ca}^{2+}$ - and $\mathrm{Mg}^{2+}$-free PBS (CMF-PBS), stored overnight $\left(4^{\circ} \mathrm{C}\right)$ in CMFPBS, and rinsed two times in a serum-free culture medium (SFM) before cell plating. The SFM consisted of 50\% (v/v) Leibovitz L-15 medium (Invitrogen, Gaithersburg, MD), 50\% (v/v) Ringer's solution (115 mM $\mathrm{KCl}, 2 \mathrm{~mm} \mathrm{CaCl}, 2.5 \mathrm{~mm} \mathrm{KCl}, 10 \mathrm{~mm}$ HEPES, $\mathrm{pH} 7.4$ ), and 1\% (w/v) BSA (Sigma). Xenopus cultures were kept at $20-22^{\circ} \mathrm{C}$ for $\sim 6 \mathrm{hr}$ before the turning assay.

Growth cone turning induced by extracellular gradients. Microscopic gradients of chemicals were produced by the pipette application method described previously (Lohof et al., 1992; Zheng et al., 1996). A standard pressure pulse of 3 psi was applied to a glass pipette ( $1 \mu \mathrm{m}$ opening $)$ at a frequency of $2 \mathrm{~Hz}$ with durations of $20 \mathrm{msec}$. The direction of growth cone extension at the beginning of the experiment was defined by the distal $20 \mu \mathrm{m}$ segment of the neurite. The pipette tip was positioned $45^{\circ}$ from the initial direction of extension and $100 \mu \mathrm{m}$ away for guidance cues. The digital images of the growth cone at the onset and end of the 30 min period were acquired and overlaid with pixel-to-pixel accuracy, and the trajectory of new neurite extension was traced using Adobe Photoshop (Adobe Systems). The turning angle was defined by the angle between the original direction of neurite extension and a line connecting the positions of the growth cone at the experiment onset and at the end of 30 min exposure to the gradient. Neurite extension was quantified by measuring the entire trajectory of net neurite growth over the $30 \mathrm{~min}$ period. Only growth cones extending $5 \mu \mathrm{m}$ or more were scored for turning responses. For bath application experiments, different drugs were added to the bath medium 20 min before the onset of gradient application. BAPTA loading was used to buffer changes in intracellular $\mathrm{Ca}^{2+}$. In brief, Xenopus cultures were incubated with BAPTAacetoxymethyl (AM) ester ( $1 \mu \mathrm{M}$; Sigma) for $30 \mathrm{~min}$, rinsed three times, and incubated with fresh SFM for 90 min before turning assay.

Microscopy and imaging for turning assay. All turning experiments were performed in an open chamber on an inverted Nikon microscope equipped either with phase-contrast optics or differential interference contrast (DIC) optics. A $20 \times$ objective was used for all of the turning experiments. A half-inch CCD video camera (C2400-75i, Hamamatsu) was used for video imaging in conjunction with an Argus-20 image processor (Hamamatsu) for image enhancement. The video images were background subtracted, averaged over four video frames, contrast enhanced in real time using the Argus-20, and digitally acquired by a personal computer (Wang and Zheng, 1998).

Fluorescent staining of membrane receptors. Xenopus neurons were rapidly fixed with $4 \%$ paraformaldehyde and $0.25 \%$ glutaraldehyde in a cacodylate buffer ( $0.1 \mathrm{~m}$ sodium cacodylate, $0.1 \mathrm{~m}$ sucrose, $\mathrm{pH} 7.4$ ) for 30 min and washed three times in $100 \%$ Ringer's saline. The cells were first incubated with $1 \%$ goat serum to block nonspecific binding sites for $1 \mathrm{hr}$ at room temperature. The cells were then incubated with a polyclonal antibody (generously provided by A. Arimura, Tulane University, New Orleans, LA) against PAC1 receptors overnight at $4^{\circ} \mathrm{C}$. After three washes, the cells were incubated with a fluorescein-conjugated goat antimouse IgG for $1 \mathrm{hr}$ at room temperature. Fluorescent imaging was performed on a Nikon inverted microscope (TE2000) using a $40 \times$ Plan Fluor oil-immersion objective with a numeric aperture (N.A.) of 1.3. Digital images were acquired by a CCD camera (PXL1400, Roper Scientific) through the use of Axon Imaging Workbench 4.0 software (Axon Instruments, Foster City, CA).

Fura-2 ratiometric imaging. Xenopus cells on glass coverslips were incubated with $8 \mu \mathrm{M}$ fura-2 AM (Molecular Probes, Eugene, OR) for 30 $\mathrm{min}$ at room temperature. They were then carefully rinsed and mounted on the stage of a Nikon inverted microscope (TE2000) equipped with a cooled CCD camera (PXL1400, Roper Scientific). A 20× Plan Fluor oil-immersion objective with N.A. of 0.75 or a $40 \times$ Plan Fluor oilimmersion objective with N.A. of 1.3 was used for imaging. Axon Imaging Workbench 4.0 was used to control the Lambda 10-2 filter wheel (Sutter Instrument) for switching excitation wavelengths and image acquisition from the CCD camera. Excitation wavelengths were 340/380 $\mathrm{nm}$, with an exposure of $100 \mathrm{msec}$ at each wavelength. Images at each wavelength were background subtracted for ratio calculation. For each experiment, the cells were imaged $1 \mathrm{~min}$ before and 3-5 min after the addition of PACAP. The acquisition rate was one ratio every $5 \mathrm{sec}$. To present the change of intracellular $\mathrm{Ca}^{2+}$ concentrations, we normalized the ratio values against the average ratio of the control period.

Focal photoactivated release of caged cAMP. The photoactivation experiments were performed on an inverted Nikon microscope (Diaphot 300) equipped with a Lambda 10-2 filter wheel and a PXL CCD camera. A UG-1 filter installed in the filter wheel was used for photoactivation. To restrict the area of photoactivation, we placed a small pinhole in front of the UG-1 filter. The actual location and size of the photoactivation were determined by imaging the photoactivated release of caged fluoresceindextran. We found that focal photoactivation by this method generated a gradient of uncaging from the center to the edge of the illumination spot. For turning experiments, the cells were incubated in the culture medium containing $1 \mu \mathrm{M}$ membrane-permeant caged cAMP (Calbiochem, La Jolla, CA) for $20 \mathrm{~min}$ before the onset of repetitive uncaging. The uncaging spot was positioned on one side of the growth cone. Repetitive photolysis was achieved by a brief opening $(50 \mathrm{msec})$ of the shutter every 10 sec for a period of $30 \mathrm{~min}$.

\section{Results}

\section{PACAP-selective receptors are present on embryonic Xenopus spinal neurons}

In Xenopus, in situ studies (Hu et al., 2001) have defined PACAP and PAC1 mRNA expression in the developing nervous system. To confirm that PACAP receptors were present in Xenopus growth cones, we examined the expression of the PACAPselective receptor PAC1 in cultured embryonic Xenopus spinal neurons. Immunocytochemical staining using a polyclonal antibody against PAC1 revealed that $>90 \%$ of the spinal neurons express PAC1 (Fig. 1a,b). The staining pattern clearly indicates the presence of PAC1 receptors on the plasma membrane. The localization of PAC1 was confirmed by comparing with the staining pattern of the lipophilic dye $\mathrm{DiIC}_{18}$, which uniformly labels the plasma membrane. PAC1 staining showed a similar distribution to $\mathrm{DiIC}_{18}$ (Fig. 1c) but appeared to be more intense at the growth cone (Fig. 1a,b, arrows). These results indicate that PAC1 receptors were indeed expressed on the surface of the neuron, including the surface of the motile growth cone, and suggest a possible role for PACAP and its receptor in neurite outgrowth and motility.

Because previous studies have shown that PACAP promotes neurite outgrowth (Deutsch and Sun, 1992; Hernandez et al., 1995; Gonzalez et al., 1997; Lu and DiCicco-Bloom, 1997; 


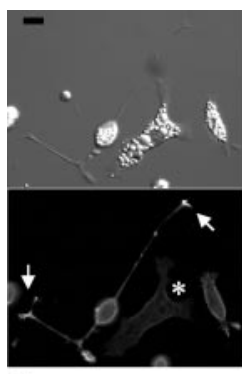

a

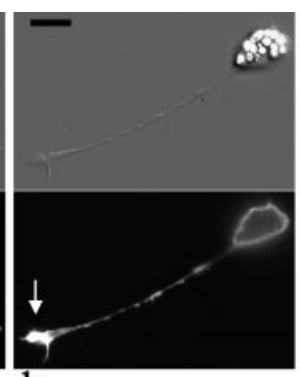

b

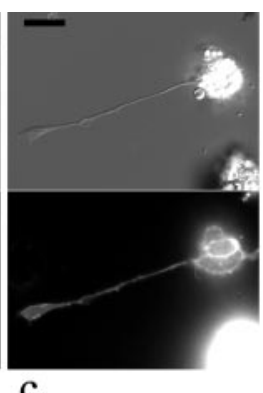

c $(n=154)$ $(n=207)$

\section{PACAP}

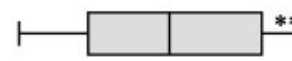

Control

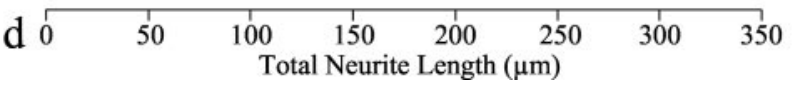

Figure 1. Expression of PACAP-selective receptors in Xenopus neurons and neurite outgrowth. $a, b$, Fluorescent images of Xenopus neurons stained using a specific antibody against $P A C 1$ receptors. Two images were acquired using a $20 \times$ objective $(a)$ and a $40 \times$ objective $(b)$. The asterisk in $a$ marks a muscle cell without PAC1 expression, and arrows indicate intense PAC1 staining at the growth cone. $c$, Fluorescent staining of the plasma membrane of a neuron using DilC ${ }_{18}$. Scale bars, $20 \mu \mathrm{m} . d$, Box and whisker plots of neurite outgrowth in the presence of control medium and media containing PACAP and VIP, respectively.

DiCicco-Bloom et al., 2000), we examined the effects of PACAP on the outgrowth of isolated Xenopus spinal neurons in culture. In this study, PACAP (10 nM) or its related peptide VIP (10 nM) was added to Xenopus cultures at the time of cell plating. Twentyfour hours later, total neurite lengths of isolated neurons (including branches) in treated and untreated cultures were measured in at least three separate experiments. Because total neurite lengths did not exhibit a normal distribution, we presented the data as box and whisker plots (Fig. 1d). Both peptides promoted neurite outgrowth as evidenced by the median total neurite lengths of the PACAP- and VIP-treated groups, 134 and $119 \mu \mathrm{m}$, respectively, whereas the median of the parallel control was $104 \mu \mathrm{m}$. The median values indicate that PACAP was more effective in promoting neurite outgrowth; statistical analysis using the Kolmogorov-Smirnov test shows that outgrowth promotion by PACAP is $\sim 10$ times more significant $(p<0.002)$ than that of VIP $(p<$ 0.02 ). Furthermore, the distribution of total neurite length of the VIP-treated group appears to exhibit greater overlap with that of the control group, suggesting the presence of neurons not responsive to VIP. The Xenopus cultures used in this study have been shown to contain heterogeneous populations of neurons that respond differentially to extrinsic factors, including neurotrophins (Lohof et al., 1993; Ming et al., 1997a). Because VIP activates PAC1 receptors only at micromolar concentrations (Harmar and Lutz, 1994), the VIP effect observed here suggests that subpopulations of cultured cells might express GPCRs that bind VIP at nanomolar concentrations, namely, VPAC1 and VPAC2. The lack of specific antibodies against the VPAC GPRCs, however, precluded direct examination of VPAC expression in Xenopus neurons.

Growth cone attraction can be induced by PACAP gradients To test whether PACAP can affect the direction of growth cone extension, we used the pipette application method (Lohof et al., 1992; Zheng et al., 1994b) to create a concentration gradient.
PACAP gradients created by pipette ejection of PACAP $(1 \mu \mathrm{M}$ in the micropipette) were found to induce marked attractive turning of the growth cone toward the pipette during the 30 min assay (Fig. 2a). The attractive effects of PACAP on Xenopus growth cones are better illustrated by the superimposed traces of the trajectory of the neurite extension of a sample population of 15 neurons (Fig. 2c). Most of the growth cones in the PACAP gradient grew and turned toward the source of PACAP. Conversely, a gradient of VIP ( $1 \mu \mathrm{M}$ in pipette) did not appear to affect the direction of growth cone extension (Fig. $2 b$ ). Composite traces also showed that pipette application of $1 \mu \mathrm{M}$ VIP or control medium did not affect the overall direction of growth cone extension (Fig. 2c). To further depict the overall response, scatter plots of the turning angle versus the net extension of all growth cones in each group are presented (Fig. $2 d$ ). For control (medium only) and VIP groups, growth cones did not exhibit a preferential turning response, and similar percentages of growth cones growing straight, toward, and away from the pipette were observed. In the group exposed to the PACAP gradient, however, most of the growth cones grew toward the pipette, resulting, on average, in a positive turning response.

We further examined the dose dependence of growth cone attraction induced by PACAP gradients. For quantitative comparison, we have presented the cumulative histogram of the distribution of turning angles (Fig. 2e), the average turning angles (Fig. 2f), and the turning scores [percentages of growth cones scored as turning positively $(+)$, negatively $(-)$, and having no turning response $(0)$ ] (Table 1 ). The control population of growth cones extended without any preferential orientation toward the application pipette. The average turning angle (in degrees) of the total 22 growth cones examined is $0.1 \pm 5.2$. Furthermore, the percentages of growth cones growing toward and away from the pipette are similar (Table 1), indicating no preferential orientation. However, when a PACAP solution ( 1 or 100 $\mu \mathrm{M})$ was applied through the micropipette, we observed marked turning responses of growth cones toward the source of PACAP (the pipette). Over 30 min of PACAP gradient exposure (1 or 100 $\mu \mathrm{M}$ PACAP in pipette), most of the growth cones (77 and $72 \%$, respectively) grew and turned toward the PACAP source; the average turning angles are $19.3 \pm 4.0$ and $16.4 \pm 3.5$, respectively. Statistical analysis using a nonparametric test (Mann-Whitney test) showed that both PACAP concentrations caused significant growth cone attraction $(p<0.01)$ when compared with the control group. When the PACAP concentration in the pipette was decreased to $10 \mathrm{nM}$, we observed no effect on the direction of growth cone extension (Fig. 2e,f, Table 1). For the gradients created by the pipette application method, the concentration of the molecule that reaches the growth cone is estimated to be $\sim 1000$ th of the concentration in the pipette (Lohof et al., 1992). Therefore, the effective PACAP concentrations inducing attraction at the growth cone are estimated to be 1 and $100 \mathrm{~nm}$ for pipette concentrations of 1 and $100 \mu \mathrm{M}$, respectively. Such effective concentrations are consistent with the reported binding affinities of PACAP for the PACAP-selective GPCR PAC1 (Harmar and Lutz, 1994).

The involvement of PAC1 receptors is strongly supported by two lines of evidence: the PAC1-specific agonist maxadilan (Moro and Lerner, 1997) induced significant growth cone attraction, whereas VIP gradients did not induce growth cone turning (Fig. 2f, Table 1). Maxadilan specifically competes for the PAC1 receptor to elicit the same functional response as PACAP (Moro and Lerner, 1997). Application of a gradient of maxadilan (1 $\mu \mathrm{M}$ in pipette) resulted in growth cone attraction that was significantly different from the control $(p<0.05$; Mann-Whitney 

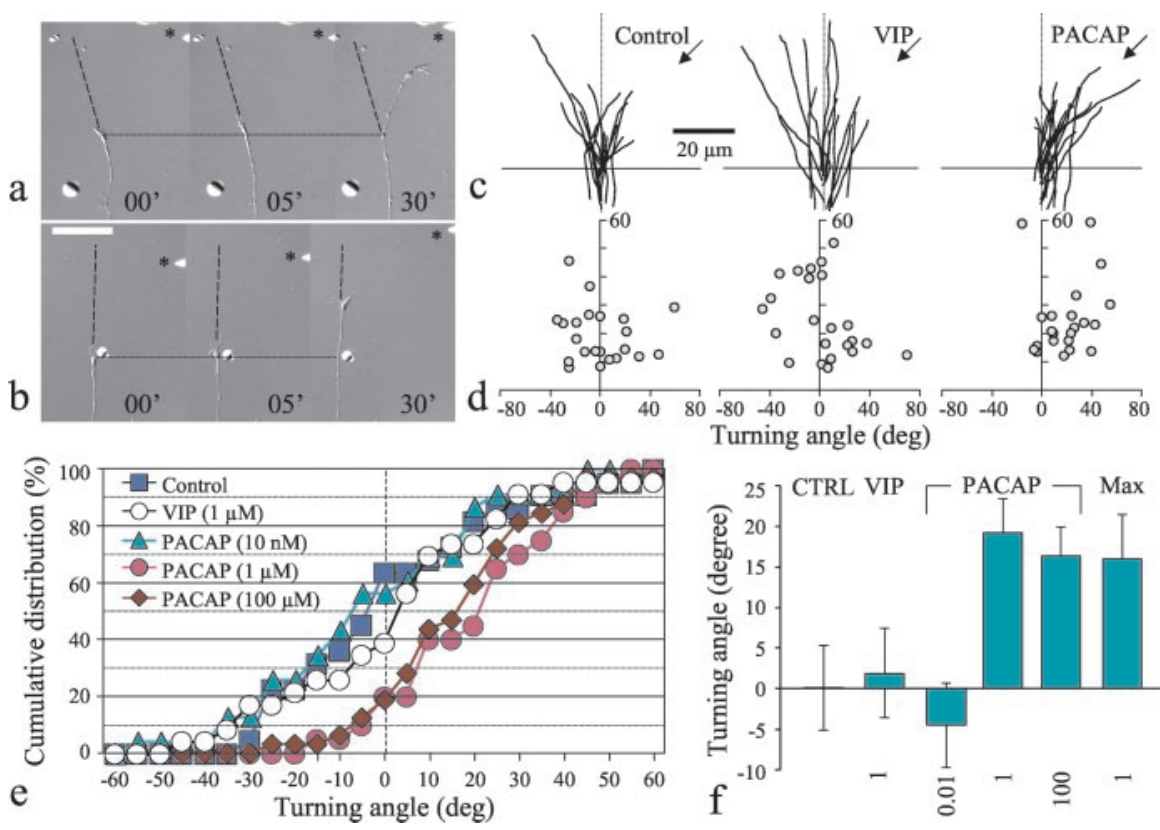

Figure 2. Attractive turning of growth cones induced by PACAP gradients. $a, b$, DIC images of representative growth cones that responded to the PACAP $(a)$ and VIP $(b)$ gradients. The concentration of PACAP or VIP in the pipette was $1 \mu \mathrm{m}$. Asterisks indicate the application pipette. Dashed lines indicate the original direction of growth cone extension, and dotted lines represent the corresponding position of the growth cone at the onset of the gradient application. Scale bar, $50 \mu \mathrm{m}$. c, Superimposed traces of the trajectory of neurite extension during the 30 min turning assay for a sample population of 15 neurons for each condition. The origin is the center of the growth cone at the onset of the gradient, and the original direction of growth cone extension was vertical. Arrows indicate the direction of the gradient. $d$, Scatter plots depict all data collected for each condition. Each point depicts final angular position of a growth cone (abscissa) and its total net neurite extension (ordinate) during the 30 min assay period. e, Cumulative histogram shows the distribution of the turning angles for each condition. Each point represents the percentage of the growth cones with final turning angles of equal or smaller values. Attractive turning response is represented by the distribution being shifted toward positive turning angles. $f$, Average turning angles of different groups of growth cones exposed to control, VIP, PACAP, and maxadilan, the PAC1-specific agonist. The values on the abscissa represent the concentrations (in micromolar) used in the pipette.

test). Conversely, turning angles induced by VIP gradients $(1 \mu \mathrm{M}$ in pipette) and that of the control group showed no statistical difference ( $p>0.5$; Mann-Whitney test). The absence of turning responses to VIP (presumptive local concentrations of $\sim 1 \mathrm{nM}$ at the growth cone) is consistent with the known inefficiency of PAC1 activation by nanomolar concentrations of VIP. It should be mentioned, however, that gradients of both PACAP and VIP appear to slightly enhance the rate of growth cone extension during the $30 \mathrm{~min}$ assay period (Table 1). Such growth-promoting effects are consistent with the outgrowth-promoting effect described above, yet only PACAP gradients were capable of inducing growth cone attraction. Taken together, these results demonstrate that PACAP can serve as a guidance molecule to effectively attract developing growth cones through the activation of PACAP-selective PAC1 GPCRs. Our data also suggest that the growth-promoting effect and the attractive effect are likely separate events.

PACAP attracts growth cones through direct cAMP signaling We next examined the signaling events that mediate the chemoattractive effects of PACAP on growth cones. PACAP was originally discovered by its ability to elevate intracellular cAMP levels by stimulating adenylate cyclases (Miyata et al., 1989). The G-proteincoupled PAC1 receptors are selectively activated by PACAP, resulting in CAMP production. We therefore tested whether the cAMP pathway is involved in PACAP-induced growth cone attraction. Because diffusible gradients created by pulsatile pipette ejection of $1 \mu \mathrm{M}$ PACAP were most effective in inducing attraction, we used this con- centration for all of the remaining experiments. To selectively block cAMP signaling, we added cAMP, Rp-isomer (Rp-cAMP) $(50 \mu \mathrm{M})$, a membrane-permeant cAMP antagonist, or KT 5720 (200 nM), a specific inhibitor of protein kinase $\mathrm{A}$, to the bath medium 20 min before the onset of the PACAP gradient. Rp-cAMP completely abolished growth cone attraction induced by PACAP (Fig. 3). Similarly, KT 5720 also abolished growth cone attraction (Fig. 3). Composite traces of a sample population of 15 neurons (Fig. 3a) as well as the scatter plots of all the growth cones examined (Fig. $3 b$ ) for each treatment reveal no preferential turning response. Furthermore, the cumulative distribution of turning angles (Fig. 3c) for both treated groups demonstrated the effective blockade of PACAP-induced attraction. Average turning angles are $-3.1 \pm 5.5$ and $2.7 \pm 4.7$ for Rp-cAMP and KT 5720, respectively, which are not different from the control group $(0.1 \pm 5.2 ; p>0.5$; MannWhitney test). Turning scores (Table 1 ) also show that both Rp-cAMP and KT 5720 blocked turning responses as similar percentages of growth cones turned toward, turned away, or grew straight. These results show that the CAMP signaling pathway is required for attractive turning induced by PACAP gradients. Moreover, during the 30 min turning assay, the average length of neurite extension in the presence of RpcAMP or KT 5720 appeared to be similar to that of the control group, but shorter than that of neurons in the PACAP gradient alone (Table 1). Thus, inhibition of the cAMP signaling pathway also appeared to abolish the growth-promoting effect of PACAP on these Xenopus neurons.

Growth cone turning responses to diffusible gradients likely involve asymmetric (or localized) signaling events that code the direction for growth cone steering. To address this issue, we used an experimental approach to uniformly elevate intracellular cAMP levels in the cell and thereby interfere with local cAMP signaling. We bath applied forskolin to activate adenylate cyclases before the onset of turning experiments. The presence of forskolin $(10 \mu \mathrm{M})$ completely blocked growth cone attraction induced by PACAP (Fig. 3, Table 1). Moreover, consistent with previous studies (Bolsover et al., 1992; Zheng et al., 1994a), bath forskolin application further increased the extension rate of these growth cones over the $30 \mathrm{~min}$ exposure. The complete abolition of PACAP-induced growth cone attraction by forskolin, together with that by Rp-cAMP and KT-5720 treatment, convincingly demonstrates that the CAMP signaling pathway mediates growth cone attraction induced by PACAP gradients. Furthermore, the forskolin data also suggest that localized cAMP elevation is involved in the directional sensing and steering of the growth cone in PACAP gradients. To further examine whether local elevation of intracellular cAMP levels is sufficient to induce growth cone attraction, we used a photoactivation method to focally release caged cAMP in the growth cone, and we then quantified the growth cone response. Repetitive photoactivated release of a caged, membrane-permeant cAMP compound on one side of the 
Table 1. Growth cone chemoattraction to PACAP gradients

\begin{tabular}{|c|c|c|c|c|c|c|c|c|c|}
\hline \multirow{2}{*}{$\begin{array}{l}\text { Chemicals in } \\
\text { pipette }\end{array}$} & \multirow[b]{2}{*}{ Chemicals in bath $^{a}$} & \multirow{2}{*}{$\begin{array}{l}\text { Pipette } \\
\text { distance } \\
(\mu \mathrm{m})\end{array}$} & \multirow{2}{*}{$\begin{array}{l}\text { Culture } \\
\text { types } \\
\text { (hr) }\end{array}$} & \multirow{2}{*}{$\begin{array}{l}\text { Turning angle } \\
{\text { (degree) })^{b}}^{\text {(d) }}\end{array}$} & \multirow{2}{*}{$\begin{array}{l}\text { Extension } \\
(\mu \mathrm{m})^{b}\end{array}$} & \multicolumn{3}{|c|}{ Turning scores (\%) } & \multirow{2}{*}{$\begin{array}{l}\text { Number } \\
\text { of cells } \\
\text { examined }\end{array}$} \\
\hline & & & & & & + & 0 & - & \\
\hline None & None & 100 & 6 & $0.1 \pm 5.2$ & $19.2 \pm 2.0$ & 36 & 18 & 46 & 22 \\
\hline 10 nм PACAP & None & 100 & 6 & $-4.5 \pm 5.2$ & $23.7 \pm 2.8$ & 39 & 4 & 57 & 23 \\
\hline $1 \mu \mathrm{M}$ РACAP & None & 100 & 6 & $19.3 \pm 4.0^{*}$ & $25.0 \pm 2.8$ & 77 & 14 & 9 & 22 \\
\hline $100 \mu \mathrm{M}$ PACAP & None & 100 & 6 & $16.4 \pm 3.5^{*}$ & $27.4 \pm 2.5$ & 72 & 16 & 12 & 32 \\
\hline $1 \mu \mathrm{m}$ maxadilan & None & 100 & 6 & $16.0 \pm 5.0^{*}$ & $22.7 \pm 2.7$ & 58 & 25 & 17 & 24 \\
\hline $1 \mu \mathrm{M}$ VIP & None & 100 & 6 & $2.0 \pm 5.5$ & $25.3 \pm 2.8$ & 43 & 22 & 35 & 23 \\
\hline $1 \mu \mathrm{M}$ РАCAP & Rp-cAMP & 100 & 6 & $-3.1 \pm 5.5$ & $19.9 \pm 2.4$ & 41 & 23 & 36 & 22 \\
\hline $1 \mu \mathrm{M}$ РАCAP & 200 пм КТ 5720 & 100 & 6 & $2.7 \pm 4.7$ & $19.1 \pm 1.8$ & 41 & 18 & 41 & 22 \\
\hline $1 \mu \mathrm{M}$ РАCAP & $10 \mu \mathrm{m}$ forskolin & 100 & 6 & $2.3 \pm 4.6$ & $27.9 \pm 3.5$ & 43 & 19 & 38 & 21 \\
\hline $1 \mu \mathrm{M}$ PACAP & $10 \mu \mathrm{m}$ Nifedipine & 100 & 6 & $17.1 \pm 5.5^{*}$ & $22.3 \pm 3.0$ & 64 & 14 & 22 & 22 \\
\hline $1 \mu \mathrm{M}$ РАCAP & (BAPTA loading) & 100 & 6 & $18.4 \pm 5.6^{*}$ & $30.6 \pm 3.5^{*}$ & 67 & 19 & 14 & 21 \\
\hline $1 \mu \mathrm{M}$ PACAP & $15 \mu \mathrm{M}$ LY 294002 & 100 & 6 & $21.3 \pm 5.8^{*}$ & $21.1 \pm 2.5$ & 72 & 14 & 14 & 21 \\
\hline $1 \mu \mathrm{M}$ РАCAP & $10 \mu \mathrm{M}$ U 73122 & 100 & 6 & $16.5 \pm 4.0^{*}$ & $22.4 \pm 2.2$ & 70 & 17 & 13 & 23 \\
\hline $500 \mu \mathrm{m}$ glutamate & None & 100 & 6 & $19.9 \pm 4.6^{*}$ & $20.2 \pm 2.4$ & 88 & 6 & 6 & 17 \\
\hline $500 \mu \mathrm{m}$ glutamate & (BAPTA loading) & 100 & 6 & $-1.6 \pm 5.1$ & $17.0 \pm 2.3$ & 41 & 24 & 35 & 17 \\
\hline $500 \mu \mathrm{m}$ glutamate & $15 \mu \mathrm{M}$ LY 294002 & 100 & 6 & $0.3 \pm 6.2$ & $21.4 \pm 3.0$ & 35 & 30 & 35 & 17 \\
\hline $500 \mu \mathrm{m}$ glutamate & $10 \mu \mathrm{M} U 73122$ & 100 & 6 & $0.0 \pm 4.0$ & $22.2 \pm 3.2$ & 47 & 11 & 41 & 17 \\
\hline $1 \mu \mathrm{M}$ PACAP & 100 pg/ml Toxin B & 100 & 6 & $0.1 \pm 4.7$ & $28.9 \pm 3.5^{*}$ & 36 & 23 & 41 & 22 \\
\hline $1 \mu \mathrm{M}$ РACAP & $40 \mu \mathrm{M}$ anisomycin & 100 & 6 & $4.4 \pm 5.1$ & $23.4 \pm 2.6$ & 40 & 40 & 20 & 25 \\
\hline $1 \mu \mathrm{M}$ РАCAP & $25 \mu \mathrm{m}$ cycloheximide & 100 & 6 & $3.7 \pm 6.4$ & $25.4 \pm 2.4$ & 41 & 23 & 36 & 22 \\
\hline
\end{tabular}

*Significantly different from the control groups ( $p<0.05$; Mann-Whitney test).

${ }^{a}$ Different drugs were added to the bath 20 min before the onset of the gradients.

${ }^{b}$ Values represent mean \pm SEM.

'Growth cone turning responses were scored as follows: plus sign $(+)$ refers to growth cones showing positive turning toward the pipette (turning angle $\left.\geq 5^{\circ}\right)$; "zero" refers to growth cones showing no turning (turning angle, $<5^{\circ}$ ); and minus sign $(-)$ refers to growth cones turning away (turning angle less than or equal to $-5^{\circ}$ ).

growth cone caused marked turning toward the center of cAMP release (Fig. 4). In aggregate, these data demonstrate that localized cAMP signaling is necessary and sufficient to direct growth cone attraction.

PACAP-induced attraction is independent of $\mathrm{Ca}^{2+}$ and phosphatidyl inositol-3 kinase signaling pathways

Different splice variants of PAC1 receptors elicit different intracellular signaling cascades besides the cAMP pathway, including PLC, PI-3 kinases, and L-type $\mathrm{Ca}^{2+}$ channels (Pisegna and Wank, 1993; Spengler et al., 1993; DiCicco-Bloom et al., 2000; Nicot and DiCicco-Bloom, 2001). To determine whether PACAP elicits $\mathrm{Ca}^{2+}$ responses in cultured Xenopus spinal neurons, we used fura-2 ratiometric imaging to measure intracellular $\mathrm{Ca}^{2+}$ concentrations $\left(\left[\mathrm{Ca}^{2+}\right]_{\mathrm{i}}\right)$. Bath application of 1 or $100 \mathrm{~nm}$ PACAP to Xenopus neurons did not elicit significant increases in $\left[\mathrm{Ca}^{2+}\right]_{\mathrm{i}}$ (Fig. 5a), making it unlikely that Xenopus neurons express PAC1 receptor splice variants coupled to $\mathrm{Ca}^{2+}$ pathways. The inability of nifedipine, a specific antagonist for L-type $\mathrm{Ca}^{2+}$ channels, to block PACAP-induced growth cone attraction also excluded the involvement of L-type $\mathrm{Ca}^{2+}$ channels in PACAP induced growth cone attraction (Table 1). To further demonstrate that $\mathrm{Ca}^{2+}$ signaling is not involved in growth cone attraction induced by PACAP gradients, Xenopus neurons were loaded with BAPTA to buffer and eliminate changes in $\left[\mathrm{Ca}^{2+}\right]_{\mathrm{i}}$ (Gomez et al., 2001). The cells were first loaded with $1 \mu \mathrm{M}$ BAPTA-AM for $30 \mathrm{~min}$, washed three times, and allowed to recover for $90 \mathrm{~min}$ before beginning the turning assay. As the positive control, we first examined the effects of BAPTA loading on $\mathrm{Ca}^{2+}$-mediated glutamate-induced growth cone attraction (Zheng et al., 1996). Although glutamate gradients induced marked attractive turning of Xenopus growth cones of untreated neurons, no turning was observed for neurons preloaded with BAPTA (Fig. $5 b$, Table 1 ), resulting in an average turning angle of $-1.6 \pm 5.1$, which is not different from the pipette application of control medium ( $p>0.5$; Mann-Whitney). Turning scores shown in Table 1 also indicate the complete blockade of glutamate-induced attraction by BAPTA. Conversely, intracellular loading of BAPTA did not affect PACAPinduced growth cone attraction; significant attractive turning was still observed in the PACAP gradient ( $1 \mu \mathrm{M}$ in pipette) (Fig. $5 c$ ). The average turning angle and the turning scores are similar to those induced by PACAP gradients alone (Table 1). This result, together with the data from $\mathrm{Ca}^{2+}$ imaging and specific inhibitors of L-type $\mathrm{Ca}^{2+}$ channels, demonstrates that $\mathrm{Ca}^{2+}$ signaling is not involved in PACAP-induced growth cone chemoattraction.

Activation of both PLC and PI-3 kinase signaling were shown to be required for netrin-1-induced growth cone turning (Ming et al., 1999). We thus examined the possible involvement of these two pathways in PACAP-induced growth cone attraction. Bath application of U73122, a specific inhibitor of PLC, or LY-294002, a specific inhibitor of PI-3 kinases, completely abolished growth cone attraction induced by glutamate gradients (Fig. 5b, Table 1), indicating that $\mathrm{Ca}^{2+}$-dependent glutamate-induced attraction requires the activation of both PLC and PI-3 kinases. For PACAP-induced growth cone attraction, however, neither U73122 nor LY-294002 blocked the turning response, and marked attraction to PACAP was still observed (Fig. $5 c$ ). The average turning angles are $16.5 \pm 4.0$ and $21.3 \pm 5.8$ for U73122 and LY-294002 groups, respectively, which are significantly different from control growth cones $(p<0.05$; Mann-Whitney test). However, no difference was observed ( $p>0.5$; MannWhitney) when compared with the group of growth cones exposed to the PACAP gradient only ( $1 \mu \mathrm{M}$ in pipette). Furthermore, $\sim 70 \%$ of the growth cones in the presence of U73122 and LY 294002 turned to the PACAP source, which is similar to the turning scores for PACAP without these inhibitors in the bath (Table 1). These data thus exclude the involvement of PLC and 

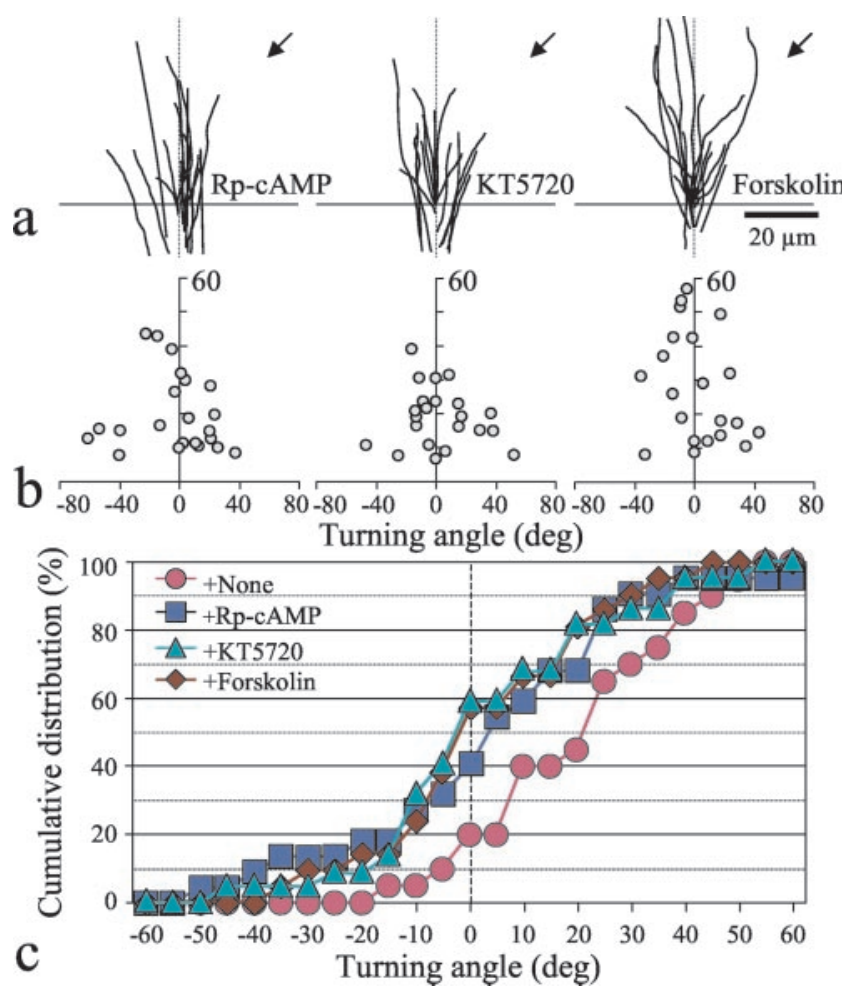

Figure 3. CAMP signaling in PACAP-induced growth cone attraction. $a$, Superimposed traces of the trajectory of neurite extension during the 30 min turning assay in a PACAP gradient $(1 \mu \mathrm{M}$ in pipette) for a sample population of 15 neurons with bath application of $50 \mu \mathrm{M}$ Rp-cAMP, 200 nм KT 5720, and $10 \mu \mathrm{m}$ forskolin. The origin is the center of the growth cone at the onset of the gradient, and the original direction of growth cone extension was vertical. Arrows indicate the direction of the gradient. $b$, Scatter plots depict all data collected for each condition. Each point depicts final angular position of a growth cone (abscissa) and its total net neurite extension (ordinate) during the $30 \mathrm{~min}$ assay period.c, Cumulative histogram shows the distribution of the turning angles for each bath application experiment. Each point represents the percentage of the growth cones with final turning angles of equal or smaller values.

PI-3 kinases in growth cone attraction induced by PACAP gradients.

\section{Requirement for Rho GTPases and protein synthesis in PACAP-induced growth cone attraction}

Although our results demonstrate that cAMP signaling directly mediates PACAP-induced growth cone attraction, downstream effectors remain to be elucidated. Growth cone motility and guidance have been shown to involve the Rho family of small GTPases that regulate cytoskeletal activities underlying growth cone motility and guidance (Hall and Nobes, 2000). We thus determined whether inhibition of the Rho GTPases could block the turning response induced by PACAP gradients. Bath application of $100 \mathrm{pg} / \mathrm{ml}$ toxin B (from Clostridium difficile) increased growth cone extension, and, significantly, it abolished the attractive response induced by PACAP (Fig. 6a, Table 1). Analysis of the cells treated in this manner revealed that similar proportions of growth cones turned toward and away from the PACAP source, and the average turning angle was close to zero (Table 1). These results suggest that Rho GTPases are also involved in cAMP-dependent growth cone attraction induced by PACAP gradients. Recent studies have also demonstrated that local protein synthesis is required for growth cone turning induced by certain guidance cues (Campbell and Holt, 2001). Therefore, we examined whether local protein synthesis is also involved in cAMP-dependent growth cone attraction induced by PACAP
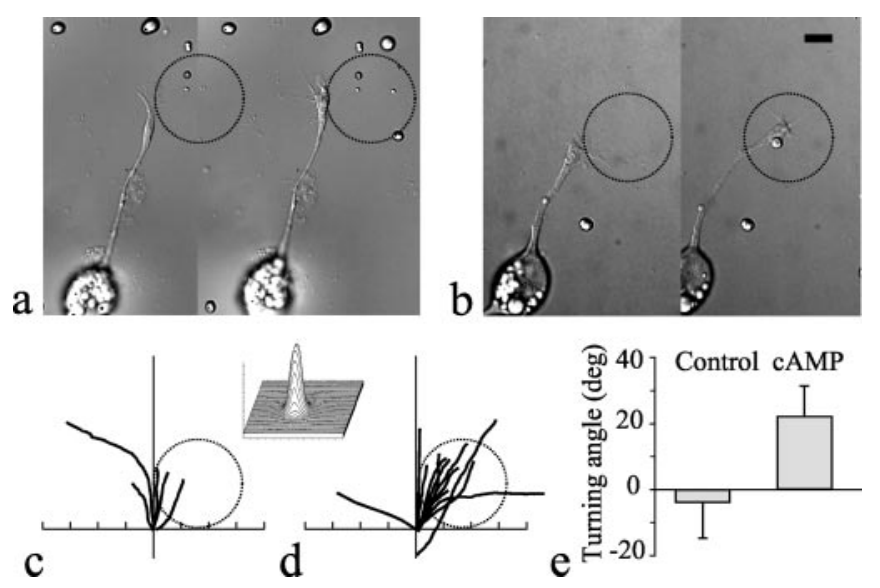

Figure 4. Growth cone turning induced by focal photoactivated release of caged cAMP. $a$, Representative DIC images showing a control growth cone (not loaded with caged CAMP) exposed to repetitive UV illumination ( $50 \mathrm{msec}$ duration, every $10 \mathrm{sec}$ ). The dotted circles indicate the position and size of the UV illumination. $b$, Representative DIC images showing a growth cone exposed to focal photoactivated release of caged cAMP. Scale bar, $10 \mu \mathrm{m}$. c, d, Superimposed traces of the trajectory of neurite extension of neurons during the 30 min repetitive focal UV illumination without ( $c$ ) and with ( $d$ ) caged cAMP loaded. Tick marks represent $10 \mu \mathrm{m}$. The three-dimensional plot depicts the fluorescence intensity generated by the focal photolysis of caged fluorescein-dextran and illustrates the spatial gradient of focal uncaging. $e$, Average turning angles of groups of growth cones exposed to control UV illumination and focal cAMP release.

gradients. Bath application of two protein synthesis inhibitors, anisomycin $(40 \mu \mathrm{M})$ and cycloheximide $(25 \mu \mathrm{M})$, entirely blocked the attractive turning induced by PACAP gradients (Fig. $6 b, c$, Table 1). Cumulative distributions of the turning angles for growth cones exposed to these two protein synthesis inhibitors showed no preferential growth cone orientation induced by PACAP (Fig. $6 d$ ), indicating the involvement of protein synthesis in PACAP-induced cAMP-dependent growth cone attraction. Our results suggest that although different signaling pathways may mediate growth cone attraction induced by different extrinsic factors, some common intracellular events might be shared and required for growth cone steering, specifically the Rho GTPases and local protein synthesis.

\section{Discussion}

Our observations provide the first evidence, to the best of our knowledge, that PACAP, a small neuropeptide widely expressed in vivo, exhibits chemotropic effects on developing growth cones. We demonstrate that cAMP signaling directly mediates growth cone attraction induced by PACAP activation of its specific GPCR, PAC1. This direct involvement of cAMP is distinct from the role of global cAMP signaling in modulating $\mathrm{Ca}^{2+}$ dependent guidance. Our findings corroborate earlier studies involving extracellular application of cAMP analogs (Gundersen and Barrett, 1980; Lohof et al., 1992) and establish a major role for cAMP signaling in growth cone guidance through G-proteincoupled receptors. Moreover, we provide a comprehensive analysis of the downstream signaling pathways, showing that $\mathrm{Ca}^{2+}$, PLC, and PI-3 kinase signaling pathways are not involved and that cAMP signaling independently mediates the attractive responses. Our studies also show that Rho GTPases and local protein synthesis are required in growth cone attraction mediated by cAMP. Because guidance by a number of guidance cues has been shown to depend on both Rho family activity and local protein synthesis and degradation (Campbell and Holt, 2001; Dickson, 2001; Ming et al., 2002; Ng et al., 2002), they are likely to be 

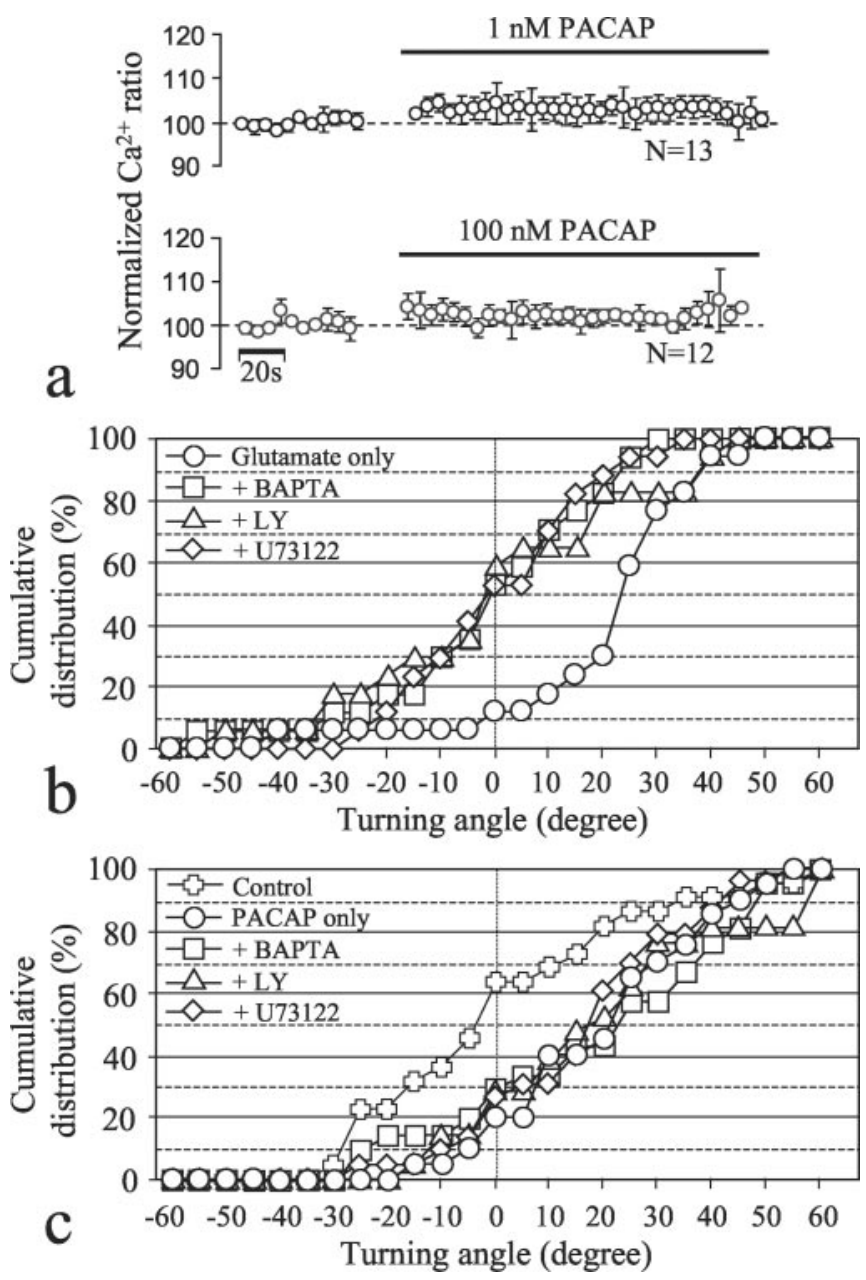

Figure 5. Examination of $\mathrm{Ca}^{2+}, \mathrm{PLC}$, and PI-3 signaling pathways in PACAP-induced growth cone attraction. $a, \mathrm{Ca}^{2+}$ responses of Xenopus neurons to bath-applied PACAP at 1 or $100 \mathrm{~nm}$ final concentrations. The fura-2 ratio (340/380 nm excitation) was normalized against the average value from the control recording period. Error bars represent SD. b, c, Cumulative histograms represent the distribution of growth cone turning angles to glutamate gradients $(b)$ or PACAP gradients $(c)$. Symbols indicate whether growth cones were preloaded with BAPTA $\left(+\right.$ BAPTA) to buffer $\left[\mathrm{Ca}^{2+}\right]_{\mathrm{i}}$ changes or treated with $15 \mu \mathrm{m} \mathrm{LY}-294002(+\angle Y)$ to inhibit PI-3 kinase or with $10 \mu \mathrm{m}$ U73122 (+U73122) to inhibit PLC.

general events required for directional steering of growth cones in response to various guidance cues.

Recent evidence suggests that GPCRs may have a role in axon guidance (Xiang et al., 2002). Our studies provide direct evidence that PACAP activation of its GPCR elicits attractive turning responses from growth cones. PACAP is capable of binding to three GPCRs, but our results provide strong evidence that PAC1, the PACAP-selective GPCR, mediates the attraction: VIP gradients were unable to exert an attractive effect, whereas gradients of the PAC1-selective agonist, maxidilan, were sufficient to induce growth cone attraction. Interestingly, VIP enhanced neurite extension in the outgrowth assays, implying that growthpromoting effects and chemotropic effects are separable, which is consistent with previous observations (Ming et al., 1997a). Potentially, growth promotion and chemoattraction could involve distinct signaling cascades. Alternatively, relatively low cAMP levels may be sufficient to enhance outgrowth, but growth cone turning may require larger increases in local cAMP levels. Relatively small increases in cAMP may be produced if subpopulations of Xenopus neurons weakly express nonselective VPAC re-
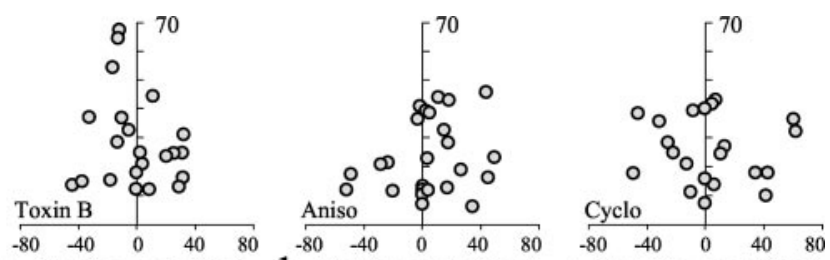

a Turning angle (deg) b Turning angle (deg) c Turning angle (deg)

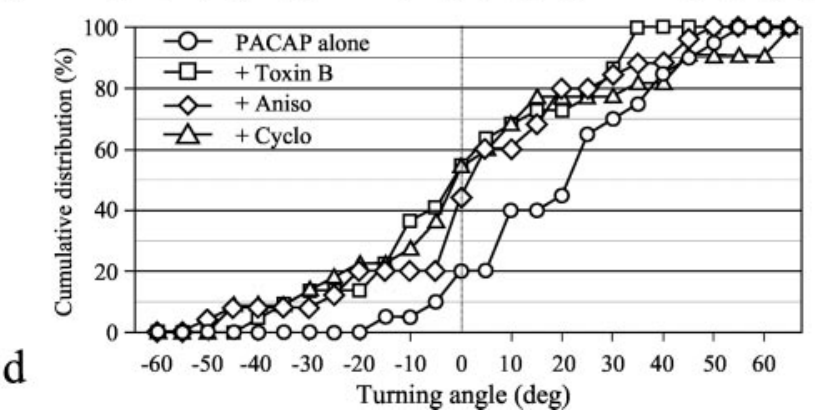

Figure 6. Involvement of Rho GTPases and local protein synthesis in PACAP-induced growth cone attraction. $a-c$, Scatter plots depict all data collected for growth cones exposed to bath application of toxin B (100 pg/ml) (a), anisomycin (Aniso; $40 \mu \mathrm{m})(b)$, and cycloheximide (Cyclo; $25 \mu \mathrm{M})(\mathrm{c})$. For all three conditions, a PACAP gradient (1 $\mu \mathrm{m}$ PACAP in pipette) was used to induce turning. Each point depicts the final angular position of a growth cone (abscissa) and its total net neurite extension (ordinate) during the $30 \mathrm{~min}$ assay period. $d$, The cumulative histogram shows the distribution of the turning angles for each bath application experiment. Each point represents the percentage of the growth cones with final turning angles of equal or smaller values.

ceptors, which can bind VIP and PACAP with equal affinity at nanomolar concentrations. Such hypotheses can be tested in further experiments, but nevertheless, the VIP and maxadilan results suggest that PACAP-induced growth cone attraction is mediated by activating the PAC1 GPCR.

Previous studies have shown that different functional outcomes from PAC1 receptors are achieved by differential coupling to distinct signaling pathways. In particular, PAC1 splice variants activate a number of signaling cascades, including the activation of adenylate cyclase, phosphatidyl inositol turnover, and L-type $\mathrm{Ca}^{2+}$ channels (Pisegna and Wank, 1993; Spengler et al., 1993; Chatterjee et al., 1996). For instance, $\mathrm{PACl}_{\text {hop }}$ splice variant activation increases $\mathrm{PI}$ turnover, protein kinase $\mathrm{C}$ localization, and intracellular $\mathrm{Ca}^{2+}$ mobilization, whereas $\mathrm{PAC} 1_{\text {short }}$ activation only stimulates adenylate cyclase (Lu et al., 1998; DiCicco-Bloom et al., 2000; Nicot and DiCicco-Bloom, 2001). Our current data demonstrate that PACAP-induced growth cone attraction was independent of $\mathrm{Ca}^{2+}$, PLC, and PI3 kinase pathways, implying that $\mathrm{PAC} 1_{\text {short }}$, not $\mathrm{PAC1} 1_{\text {hop }}$, likely mediates the turning. Further experiments are required to determine which splice variants are expressed in our cultures and if differential splice variant expression can be correlated with growth cone turning and growth promotion.

One of the most significant findings of this study is the demonstration that direct cAMP signaling can mediate growth cone attraction, independent of $\mathrm{Ca}^{2+}$ and PI-3 kinase pathways. Although previous evidence has suggested a role for cAMP signaling in growth cone guidance, those studies emphasize a modulatory role for the cAMP pathway in growth cone turning responses to guidance molecules. In previous reports, global inhibition or elevation of intracellular cAMP levels in the neuron did not block turning responses; instead, such treatments resulted in conversion from attraction to repulsion or vice versa (Ming et al., 1997b; Song et al., 1997, 1998; Hopker et al., 1999). Although an extra- 
cellular gradient of membrane-permeant cAMP analogs was shown to induce growth cone attraction (Gundersen and Barrett, 1980; Lohof et al., 1992), these reports did not examine other signaling components, e.g., calcium signaling. Recent studies indicated that multiple levels of interactions between $\mathrm{Ca}^{2+}$ and cAMP pathways exist (Eliot et al., 1993; Cooper et al., 1995; Wayman et al., 1995; Mons et al., 1998; Haug et al., 1999; Gorbunova and Spitzer, 2002). Therefore, it was not clear whether growth cone attraction induced by extracellular gradients of cAMP analogs was mediated directly by intracellular cAMP signals or by other pathways affected by cAMP (e.g., $\mathrm{Ca}^{2+}$ ). Moreover, it was not known whether these treatments produced physiological levels of cAMP in the growth cone to induce turning (Lohof et al., 1992). In contrast, we used a physiologically relevant polypeptide to activate its G-protein-coupled receptor; activation of the receptor then in turn activated the adenylate cyclases, presumably through $G \alpha_{\text {s }}$ subunits, to elevate intracellular cAMP levels. It is likely that cAMP production induced by PACAP is comparable with that elicited by activation of other G-protein-coupled receptors. Furthermore, we have determined the downstream signals that mediate PACAP-induced attraction and have excluded $\mathrm{Ca}^{2+}$, PLC, and PI-3 kinase signaling pathways. In marked contrast, the turning responses induced by group I guidance cues including netrin-1 and brain-derived neurotrophic factor are modulated by the cAMP pathway and require PLC and PI-3 activation (Song and Poo, 1999). Thus, we conclude that PACAPinduced guidance is mechanistically different from that by group I molecules.

Our study indicates that protein synthesis and Rho GTPase activity are general components required for growth cone guidance, including PACAP-induced attraction. Campbell and Holt (2001) have shown that netrin-1 and Sema3A use different pathways to regulate translation and growth cone turning responses; in particular, PI-3 kinase was involved only in the former case. Our results provide evidence that PI-3 kinase is not required for PACAP-induced attraction, although protein synthesis is required. The Rho GTPases are small GTPases that regulate the actin cytoskeleton (Hall and Nobes, 2000) and have been previously shown to play important roles in axon guidance and other forms of cellular motility (Dickson, 2001; Ng et al., 2002). Recent studies suggest that PKA can regulate the activity of Rho GTPases (Lang et al., 1996; Laudanna et al., 1997; O'Connor and Mercurio, 2001). Other candidate PKA targets likely to be regulated during axon guidance include members of the Enabled (Ena)/ Vasodilator-stimulated phosphoprotein (VASP) family, which have been implicated in the regulation of actin-based motility. In particular, the Ena/VASP-like protein binds its ligands in a manner that depends on PKA phosphorylation (Lambrechts et al., 2000). It remains to be determined whether any members of the Rho GTPases and Ena/VASP are the direct targets of protein kinase A during PACAP-induced attraction. Our toxin B data demonstrate only the requirement of Rho GTPase activity in PACAP-induced attraction. It is possible that the activity of Rho GTPases, although not directly downstream of PKA, is generally required for cytoskeletal activities responsible for growth cone directional motility, including cross-talk between the actin and microtubule cytoskeleton (Buck and Zheng, 2002; Fukata et al., 2002; Krendel et al., 2002).

The presence of PACAP and its receptors in developing neurons suggests a potential role for PACAP in axon guidance during neural development. Our study presents the first evidence that PACAP has chemotropic effects on developing neurons in vitro; however, the specific in vivo interactions remain to be investi- gated. PACAP-27 and PACAP-38 are two active forms of the peptide that may result from the post-translational cleavage of a propeptide precursor. Because both the 27- and 38-amino acid peptides have shown similar functional properties in vitro and in vivo, all of the experiments described here were conducted with PACAP-38. PACAP peptides exhibit neurotrophic effects on developing neurons; activation of $\mathrm{PAC1}$ receptors by PACAP promotes precursor mitosis, neuronal survival, neurite outgrowth and differentiation, and neurotransmission (Waschek, 2002). In addition to its role during development, PACAP exhibits protective effects on neuronal death (Shoge et al., 1999; Silveira et al., 2002). During Xenopus development, PACAP and its PAC1 receptors are expressed in the brain and spinal cord; shortly after neural tube closure, PACAP mRNA was detected dorsolaterally, whereas PAC1 mRNA was localized ventrally in the anterior spinal cord (Hu et al., 2001). Therefore, PACAP-PAC1 interactions could potentially play a role in growth cone motility and guidance in vivo. It would also be interesting to determine whether PACAP-PAC1 interactions provide an autocrine system for growth cone motility because some neurons have been shown to simultaneously express PACAP and its receptors ( $\mathrm{Lu}$ and DiCicco-Bloom, 1997). It seems reasonable that an autocrine loop would likely promote the rate of neurite extension; potentially, asymmetric inhibition of autocrine PACAP-PAC1 interactions at the growth cone could also influence the direction of growth cone extension. Finally, local PACAP-PAC1 interaction at synapses (Otto et al., 1999, 2001; Roberto and Brunelli, 2000; Hamelink et al., 2002) could be involved in the final stages of guidance or in structural plasticity (i.e., new neurite sprouts could be elicited and attracted to establish more connections). The possible effects of PACAP on growth cone guidance and other aspects of development will undoubtedly provide interesting avenues for future studies.

In conclusion, our study has demonstrated direct cAMP signaling through G-protein-coupled receptor activation in growth cone attraction induced by the neuropeptide PACAP. These results extend the functional repertoire of PACAP and its receptor in neuronal development. Furthermore, our findings suggest the possibility that other guidance cues may signal through the cAMP pathway, including many extrinsic factors that act on G-proteincoupled receptors. Stimulation and inhibition of adenylate cyclases have been observed for many of these factors. A gradient of these factors, through their asymmetric influence on intracellular cAMP levels at the growth cone, could impact the direction of axonal growth and guide them in local and distant manners, allowing precise wiring of specific neuronal connections.

\section{References}

Arimura A (1992) Pituitary adenylate cyclase activating polypeptide (PACAP): discovery and current status of research. Regul Pept 37:287-303.

Bolsover SR, Gilbert SH, Spector I (1992) Intracellular cyclic AMP produces effects opposite to those of cyclic GMP and calcium on shape and motility of neuroblastoma cells. Cell Motil Cytoskeleton 22:99-116.

Buck KB, Zheng JQ (2002) Growth cone turning induced by direct local modification of microtubule dynamics. J Neurosci 22:9358-9367.

Campbell DS, Holt CE (2001) Chemotropic responses of retinal growth cones mediated by rapid local protein synthesis and degradation. Neuron 32:1013-1026.

Chartrel N, Tonon MC, Vaudry H, Conlon JM (1991) Primary structure of frog pituitary adenylate cyclase-activating polypeptide (PACAP) and effects of ovine PACAP on frog pituitary. Endocrinology 129:3367-3371.

Chatterjee TK, Sharma RV, Fisher RA (1996) Molecular cloning of a novel variant of the pituitary adenylate cyclase-activating polypeptide (PACAP) 
receptor that stimulates calcium influx by activation of L-type calcium channels. J Biol Chem 271:32226-32232.

Cooper DM, Mons N, Karpen JW (1995) Adenylyl cyclases and the interaction between calcium and cAMP signalling. Nature 374:421-424.

Deutsch PJ, Sun Y (1992) The 38-amino acid form of pituitary adenylate cyclase-activating polypeptide stimulates dual signaling cascades in PC12 cells and promotes neurite outgrowth. J Biol Chem 267:5108-5113.

DiCicco-Bloom E, Deutsch PJ, Maltzman J, Zhang J, Pintar JE, Zheng J, Friedman WF, Zhou X, Zaremba T (2000) Autocrine expression and ontogenetic functions of the PACAP ligand/receptor system during sympathetic development. Dev Biol 219:197-213.

Dickson BJ (2001) Rho GTPases in growth cone guidance. Curr Opin Neurobiol 11:103-110.

Eliot LS, Kandel ER, Siegelbaum SA, Blumenfeld H (1993) Imaging terminals of Aplysia sensory neurons demonstrates role of enhanced $\mathrm{Ca}^{2+}$ influx in presynaptic facilitation. Nature 361:634-637.

Fukata M, Watanabe T, Noritake J, Nakagawa M, Yamaga M, Kuroda S, Matsuura Y, Iwamatsu A, Perez F, Kaibuchi K (2002) Rac1 and Cdc42 capture microtubules through IQGAP1 and CLIP-170. Cell 109:873-885.

Gomez TM, Robles E, Poo M, Spitzer NC (2001) Filopodial calcium transients promote substrate-dependent growth cone turning. Science 291:1983-1987.

Gonzalez BJ, Basille M, Vaudry D, Fournier A, Vaudry H (1997) Pituitary adenylate cyclase-activating polypeptide promotes cell survival and neurite outgrowth in rat cerebellar neuroblasts. Neuroscience 78:419-430.

Gorbunova YV, Spitzer NC (2002) Dynamic interactions of cyclic AMP transients and spontaneous $\mathrm{Ca}\left({ }^{2+}\right)$ spikes. Nature 418:93-96.

Gundersen RW, Barrett JN (1980) Characterization of the turning response of dorsal root neurites toward nerve growth factor. J Cell Biol 87:546-554.

Hall A, Nobes CD (2000) Rho GTPases: molecular switches that control the organization and dynamics of the actin cytoskeleton. Philos Trans R Soc Lond B Biol Sci 355:965-970.

Hamelink C, Tjurmina O, Damadzic R, Young WS, Weihe E, Lee HW, Eiden LE (2002) Pituitary adenylate cyclase-activating polypeptide is a sympathoadrenal neurotransmitter involved in catecholamine regulation and glucohomeostasis. Proc Natl Acad Sci USA 99:461-466.

Harmar T, Lutz E (1994) Multiple receptors for PACAP and VIP. Trends Pharmacol Sci 15:97-99.

Haug LS, Jensen V, Hvalby O, Walaas SI, Ostvold AC (1999) Phosphorylation of the inositol 1,4,5-trisphosphate receptor by cyclic nucleotidedependent kinases in vitro and in rat cerebellar slices in situ. J Biol Chem 274:7467-7473.

Hernandez A, Kimball B, Romanchuk G, Mulholland MW (1995) Pituitary adenylate cyclase-activating peptide stimulates neurite growth in PC12 cells. Peptides 16:927-932.

Hong K, Nishiyama M, Henley J, Tessier-Lavigne M, Poo M (2000) Calcium signalling in the guidance of nerve growth by netrin-1. Nature 403:93-98.

Hopker VH, Shewan D, Tessier-Lavigne M, Poo M, Holt C (1999) Growthcone attraction to netrin-1 is converted to repulsion by laminin-1. Nature 401:69-73

Hu Z, Lelievre V, Rodriguez WI, Tam J, Cheng JW, Cohen-Cory S, Waschek JA (2001) Embryonic expression of pituitary adenylyl cyclase-activating polypeptide and its selective type I receptor gene in the frog Xenopus laevis neural tube. J Comp Neurol 441:266-275.

Krendel M, Zenke FT, Bokoch GM (2002) Nucleotide exchange factor GEF-H1 mediates cross-talk between microtubules and the actin cytoskeleton. Nat Cell Biol 4:294-301.

Kuhn TB, Williams CV, Dou P, Kater SB (1998) Laminin directs growth cone navigation via two temporally and functionally distinct calcium signals. J Neurosci 18:184-194.

Lambrechts A, Kwiatkowski AV, Lanier LM, Bear JE, Vandekerckhove J, Ampe C, Gertler FB (2000) cAMP-dependent protein kinase phosphorylation of EVL, a Mena/VASP relative, regulates its interaction with actin and SH3 domains. J Biol Chem 275:36143-36151.

Lang P, Gesbert F, Delespine-Carmagnat M, Stancou R, Pouchelet M, Bertoglio J (1996) Protein kinase A phosphorylation of RhoA mediates the morphological and functional effects of cyclic AMP in cytotoxic lymphocytes. EMBO J 15:510-519.

Laudanna C, Campbell JJ, Butcher EC (1997) Elevation of intracellular cAMP inhibits RhoA activation and integrin-dependent leukocyte adhesion induced by chemoattractants. J Biol Chem 272:24141-24144.

Lohof AM, Quillan M, Dan Y, Poo MM (1992) Asymmetric modulation of cytosolic cAMP activity induces growth cone turning. J Neurosci 12:1253-1261.

Lohof AM, Ip NY, Poo MM (1993) Potentiation of developing neuromuscular synapses by the neurotrophins NT-3 and BDNF. Nature 363:350-353.

Lu N, DiCicco-Bloom E (1997) Pituitary adenylate cyclase-activating polypeptide is an autocrine inhibitor of mitosis in cultured cortical precursor cells. Proc Natl Acad Sci USA 94:3357-3362.

Lu N, Zhou R, DiCicco-Bloom E (1998) Opposing mitogenic regulation by PACAP in sympathetic and cerebral cortical precursors correlates with differential expression of PACAP receptor (PAC1-R) isoforms. J Neurosci Res 53:651-662.

Ming G, Song H, Berninger B, Inagaki N, Tessier-Lavigne M, Poo M (1999) Phospholipase C-gamma and phosphoinositide 3-kinase mediate cytoplasmic signaling in nerve growth cone guidance. Neuron 23:139-148.

Ming GL, Lohof AM, Zheng JQ (1997a) Acute morphogenic and chemotropic effects of neurotrophins on cultured embryonic Xenopus spinal neurons. J Neurosci 17:7860-7871.

Ming GL, Song HJ, Berninger B, Holt CE, Tessier-Lavigne M, Poo MM (1997b) cAMP-dependent growth cone guidance by Netrin-1. Neuron 19:1225-1235.

Ming GL, Wong ST, Henley J, Yuan XB, Song HJ, Spitzer NC, Poo MM (2002) Adaptation in the chemotactic guidance of nerve growth cones. Nature 417:411-418.

Miyata A, Arimura A, Dahl RR, Minamino N, Uehara A, Jiang L, Culler MD, Coy DH (1989) Isolation of a novel 38 residue-hypothalamic polypeptide which stimulates adenylate cyclase in pituitary cells. Biochem Biophys Res Commun 164:567-574

Mons N, Decorte L, Jaffard R, Cooper DM (1998) $\mathrm{Ca}^{2+}$-sensitive adenylyl cyclases, key integrators of cellular signalling. Life Sci 62:1647-1652.

Moro O, Lerner EA (1997) Maxadilan, the vasodilator from sand flies, is a specific pituitary adenylate cyclase activating peptide type I receptor agonist. J Biol Chem 272:966-970.

Ng J, Nardine T, Harms M, Tzu J, Goldstein A, Sun Y, Dietzl G, Dickson BJ, Luo L (2002) Rac GTPases control axon growth, guidance and branching. Nature 416:442-447.

Nicot A, DiCicco-Bloom E (2001) Regulation of neuroblast mitosis is determined by PACAP receptor isoform expression. Proc Natl Acad Sci USA 98:4758-4763.

O'Connor KL, Mercurio AM (2001) Protein kinase A regulates Rac and is required for the growth factor-stimulated migration of carcinoma cells. J Biol Chem 276:47895-47900.

Otto C, Zuschratter W, Gass P, Schutz G (1999) Presynaptic localization of the PACAP-type I-receptor in hippocampal and cerebellar mossy fibres. Brain Res Mol Brain Res 66:163-174.

Otto C, Kovalchuk Y, Wolfer DP, Gass P, Martin M, Zuschratter W, Grone HJ, Kellendonk C, Tronche F, Maldonado R, Lipp HP, Konnerth A, Schutz G (2001) Impairment of mossy fiber long-term potentiation and associative learning in pituitary adenylate cyclase activating polypeptide type I receptor-deficient mice. J Neurosci 21:5520-5527.

Pisegna JR, Wank SA (1993) Molecular cloning and functional expression of the pituitary adenylate cyclase-activating polypeptide type I receptor. Proc Natl Acad Sci USA 90:6345-6349.

Roberto M, Brunelli M (2000) PACAP-38 enhances excitatory synaptic transmission in the rat hippocampal CA1 region. Learn Mem 7:303-311.

Sherwood NM, Krueckl SL, McRory JE (2000) The origin and function of the pituitary adenylate cyclase-activating polypeptide (PACAP)/glucagon superfamily. Endocr Rev 21:619-670.

Shoge K, Mishima HK, Saitoh T, Ishihara K, Tamura Y, Shiomi H, Sasa M (1999) Attenuation by PACAP of glutamate-induced neurotoxicity in cultured retinal neurons. Brain Res 839:66-73.

Silveira MS, Costa MR, Bozza M, Linden R (2002) Pituitary adenylyl cyclase-activating polypeptide prevents induced cell death in retinal tissue through activation of cyclic AMP-dependent protein kinase. J Biol Chem 277:16075-16080.

Song H, Ming G, He Z, Lehmann M, McKerracher L, Tessier-Lavigne M, Poo M (1998) Conversion of neuronal growth cone responses from repulsion to attraction by cyclic nucleotides. Science 281:1515-1518.

Song HJ, Poo MM (1999) Signal transduction underlying growth cone guidance by diffusible factors. Curr Opin Neurobiol 9:355-363.

Song HJ, Ming GL, Poo MM (1997) cAMP-induced switching in turning direction of nerve growth cones. Nature 388:275-279. 
Spengler D, Waeber C, Pantaloni C, Holsboer F, Bockaert J, Seeburg PH, Journot L (1993) Differential signal transduction by five splice variants of the PACAP receptor. Nature 365:170-175.

Spitzer NC, Lamborghini JE (1976) The development of the action potential mechanism of amphibian neurons isolated in culture. Proc Natl Acad Sci USA 73:1641-1645.

Tessier-Lavigne M, Goodman CS (1996) The molecular biology of axon guidance. Science 274:1123-1133.

Vaudry D, Gonzalez BJ, Basille M, Yon L, Fournier A, Vaudry H (2000) Pituitary adenylate cyclase-activating polypeptide and its receptors: from structure to functions. Pharmacol Rev 52:269-324.

Wang Q, Zheng JQ (1998) Cyclic AMP-mediated regulation of neurotrophininduced collapse of nerve growth cones. J Neurosci 18:4973-4984.

Waschek JA (2002) Multiple actions of pituitary adenylyl cyclase activating peptide in nervous system development and regeneration. Dev Neurosci 24:14-23.

Wayman GA, Hinds TR, Storm DR (1995) Hormone stimulation of type III adenylyl cyclase induces $\mathrm{Ca}^{2+}$ oscillations in HEK-293 cells. J Biol Chem 270:24108-24115.

Xiang Y, Li Y, Zhang Z, Cui K, Wang S, Yuan XB, Wu CP, Poo MM, Duan S (2002) Nerve growth cone guidance mediated by G protein-coupled receptors. Nat Neurosci 5:843-848.

Zhang Q, Mason CA (1998) Developmental regulation of mossy fiber afferent interactions with target granule cells. Dev Biol 195:75-87.

Zheng JQ (2000) Turning of nerve growth cones induced by localized increases in intracellular calcium ions. Nature 403:89-93.

Zheng JQ, Zheng Z, Poo M (1994a) Long-range signaling in growing neurons after local elevation of cyclic AMP-dependent activity. J Cell Biol 127:1693-1701.

Zheng JQ, Felder M, Connor JA, Poo MM (1994b) Turning of nerve growth cones induced by neurotransmitters. Nature 368:140-144.

Zheng JQ, Wan JJ, Poo MM (1996) Essential role of filopodia in chemotropic turning of nerve growth cone induced by a glutamate gradient. J Neurosci 16:1140-1149. 